\title{
Design of and technical challenges involved in a framework for multicentric radiotherapy treatment planning studies
}

Citation for published version (APA):

Roelofs, E., Persoon, L., Qamhiyeh, S., Verhaegen, F., De Ruysscher, D., Scholz, M., lancu, G., Engelsman, M., Rasch, C. R., Zijp, L., De Meerleer, G., Coghe, M., Langendijk, J. A., Schilstra, C., PijlsJohannesma, M., \& Lambin, P. (2010). Design of and technical challenges involved in a framework for multicentric radiotherapy treatment planning studies. Radiotherapy and Oncology, 97(3), 567-571. https://doi.org/10.1016/j.radonc.2010.08.009

Document status and date:

Published: 01/12/2010

DOI:

10.1016/j.radonc.2010.08.009

Document Version:

Publisher's PDF, also known as Version of record

Document license:

Taverne

Please check the document version of this publication:

- A submitted manuscript is the version of the article upon submission and before peer-review. There can be important differences between the submitted version and the official published version of record.

People interested in the research are advised to contact the author for the final version of the publication, or visit the DOI to the publisher's website.

- The final author version and the galley proof are versions of the publication after peer review.

- The final published version features the final layout of the paper including the volume, issue and page numbers.

Link to publication

\footnotetext{
General rights rights.

- You may freely distribute the URL identifying the publication in the public portal. please follow below link for the End User Agreement:

www.umlib.nl/taverne-license

Take down policy

If you believe that this document breaches copyright please contact us at:

repository@maastrichtuniversity.nl

providing details and we will investigate your claim.
}

Copyright and moral rights for the publications made accessible in the public portal are retained by the authors and/or other copyright owners and it is a condition of accessing publications that users recognise and abide by the legal requirements associated with these

- Users may download and print one copy of any publication from the public portal for the purpose of private study or research.

- You may not further distribute the material or use it for any profit-making activity or commercial gain

If the publication is distributed under the terms of Article 25fa of the Dutch Copyright Act, indicated by the "Taverne" license above, 
Quality assurance

\title{
Design of and technical challenges involved in a framework for multicentric radiotherapy treatment planning studies
}

\author{
Erik Roelofs a , Lucas Persoon ${ }^{a}$, Sima Qamhiyeh ${ }^{\mathrm{a}, 1}$, Frank Verhaegen ${ }^{\mathrm{a}, \mathrm{b}}$, Dirk De Ruysscher ${ }^{\mathrm{a}}$, Michael Scholz ${ }^{\mathrm{c}}$, \\ Gheorghe Iancu ${ }^{c}$, Martijn Engelsman ${ }^{\mathrm{d}}$, Coen Rasch ${ }^{\mathrm{e}}$, Lambert Zijp ${ }^{\mathrm{e}}$, Gert De Meerleer ${ }^{\mathrm{f}}$, Marc Coghe ${ }^{\mathrm{f}}$, \\ Johannes Langendijk ${ }^{\mathrm{g}}$, Cornelis Schilstra ${ }^{\mathrm{g}}$, Madelon Pijls-Johannesma ${ }^{\mathrm{a}, 2, *}$, Philippe Lambin ${ }^{\mathrm{a}, 2,3}$ \\ ${ }^{\text {a }}$ Department of Radiation Oncology (MAASTRO), Maastricht University Medical Centre, The Netherlands; ${ }^{\mathrm{b}}$ McGill University, Montreal, Canada; ${ }^{\mathrm{c}}$ Gesellschaft für \\ Schwerionenforschung, Darmstadt, Germany; ${ }^{\mathrm{d}}$ Massachusetts General Hospital/Harvard Medical School, Boston, MA, USA; ${ }^{\mathrm{e}}$ Netherlands Cancer Institute, Amsterdam, \\ The Netherlands; ${ }^{\mathrm{f}}$ University Hospital Ghent, Belgium; ${ }^{\mathrm{g}}$ University Medical Center Groningen, University of Groningen, The Netherlands
}

\section{A R T I C L E I N F O}

\section{Article history:}

Received 14 April 2009

Received in revised form 6 April 2010

Accepted 12 August 2010

Available online 21 September 2010

\section{Keywords:}

Treatment planning studies

In silico

Radiotherapy

Multicentric

Clinical trial

Quality assurance

Public repositories

Data pooling

\begin{abstract}
A B S T R A C T
This report introduces a framework for comparing radiotherapy treatment planning in multicentric in silico clinical trials. Quality assurance, data incompatibility, transfer and storage issues, and uniform analysis of results are discussed. The solutions that are given provide a useful guide for the set-up of future multicentric planning studies or public repositories of high quality data.
\end{abstract}

(C) 2010 Elsevier Ireland Ltd. All rights reserved. Radiotherapy and Oncology 97 (2010) 567-571
In radiation oncology, in silico clinical trials or planning studies are increasingly popular for investigating different treatment options without harming the patient [1-3]. They can be described as modelling studies that, based on virtual patient material (imaging), validated procedures (including a priori sample size calculation) and models, providing an alternative method of exploring

* Corresponding author. Address: MAASTRO cuInIc, Dr Tanslaan 12, 6229 ET, Maastricht, The Netherlands.

E-mail address: madelon.pijls@maastro.nl (M. Pijls-Johannesma).

1 Present address: Westdeutsches Protonentherapiezentrum Essen (WPE), Germany.

2 These authors contributed equally to this work.

3 On behalf of the ROCOCO consortium: JL Habrand, A Mazal (Centre de Protontherapie d'Orsay, FR); AE Nahum (Clatterbridge Centre for Oncology, UK); G Iancu, M Krämer, M Scholz (Gesellschaft für Schwerionenforschung, DE); J Debus, O Jäkel (Heidelberger Ionenstrahl-Therapiezentrum, DE); BG Baumert, AL Dekker, D De Ruysscher, P Lambin, LC Persoon, M Pijls-Johannesma, E Roelofs, F Verhaegen (MAASTRO CLINIC, NL); M Engelsman (Massachusetts General Hospital and Harvard Medical School, USA); M Baba, T Hirohiko, N Kanematsu (National Institute of Radiological Sciences, JA); CR Rasch, M Verheij, LJ Zijp (Netherlands Cancer Institute, $\mathrm{NL}$ ); A Lomax, JM Schippers (Paul Scherrer Institut, $\mathrm{CH}$ ); M Eble (University Hospital Aachen, DE); F Ammazzalorso, U Jelen (University Hospital Giessen and Marburg); M Coghe, G De Meerleer, W De Neve, V Fonteyne, I Madani (University Hospital Ghent, BE); JA Langendijk, C Schilstra, TA van de Water (University Medical Center Groningen, NL) or generating hypotheses. The modelling results should then be validated in real life with prospective clinical trials [4].

The concept of treatment planning comparison studies is not new. Starting in the early 80s, the National Cancer Institute funded various projects to evaluate and compare different treatment modalities $[5,6]$. Back then, a lot of tools and procedures we now take for granted (e.g. 3D dose evaluation, multi-modal image registration, and plan optimisation) were missing or insufficiently implemented. This hindered the proceedings of those projects. In the three decades that followed a lot of these issues were overcome. Although the comparison of radiotherapy treatment options in a multicentric setting is still challenging it is much less problematic as in the early days.

One such multicentric in silico clinical trial that is based on the MISTIR (acronym for “Multicentric In Silico Trials In Radiotherapy") framework presented here is ROCOCO (Radiation Oncology Collaborative Comparison) [7]. This is an emulation of clinical trials in photon, proton and heavier particle radiotherapy for tumours with high incidence. It comprises the treatment planning (TP) comparison of lung, prostate and head and neck tumours for 25 patients in each group. Currently, eight international institutes are performing TP for conventional and intensity-modulated photon, passive scattered, scanning or intensity-modulated proton and carbon ion 
radiotherapy. MAASTRO cLINIC serves as the coordinating Data Centre (DC) as well as being a participant.

During the course of the project various organisational and technical issues arose and were solved, thus maturing the framework into its current state (Fig. 1). As we believe that the set-up is an all-in-one solution that can be used for a wide range of in silico clinical trials in radiotherapy, planning studies and/or for public repository of anonymised datasets, our intention with this technical note is to provide a step-by-step guide for building such a framework. All major action blocks will be discussed and critical issues on data exchange will be explored. Information that is kept up-to-date can be found online on the MISTIR website: http:// www.mistir.info.

\section{Methods}

For an international, multicentric in silico clinical trial that started in January 2008 a framework was built using five major action blocks (Fig. 1). A centrally hosted database (DB) was designed to host the protocol, the patient datasets, the TP results and the analysis thereof. Secure access to the database was granted to authorised project participants by means of the FTPS (secured File Transfer Protocol) and HTTPS (secured Hyper Text Transfer Protocol) protocols $[8,9]$. We used Public Key Infrastructure (PKI) certificates (the gold standard security method in data exchange of medical data [10-12]) to verify the user's identity before login was allowed.

To facilitate data sharing, the participants agreed to use the internationally accepted Digital Imaging and Communications in

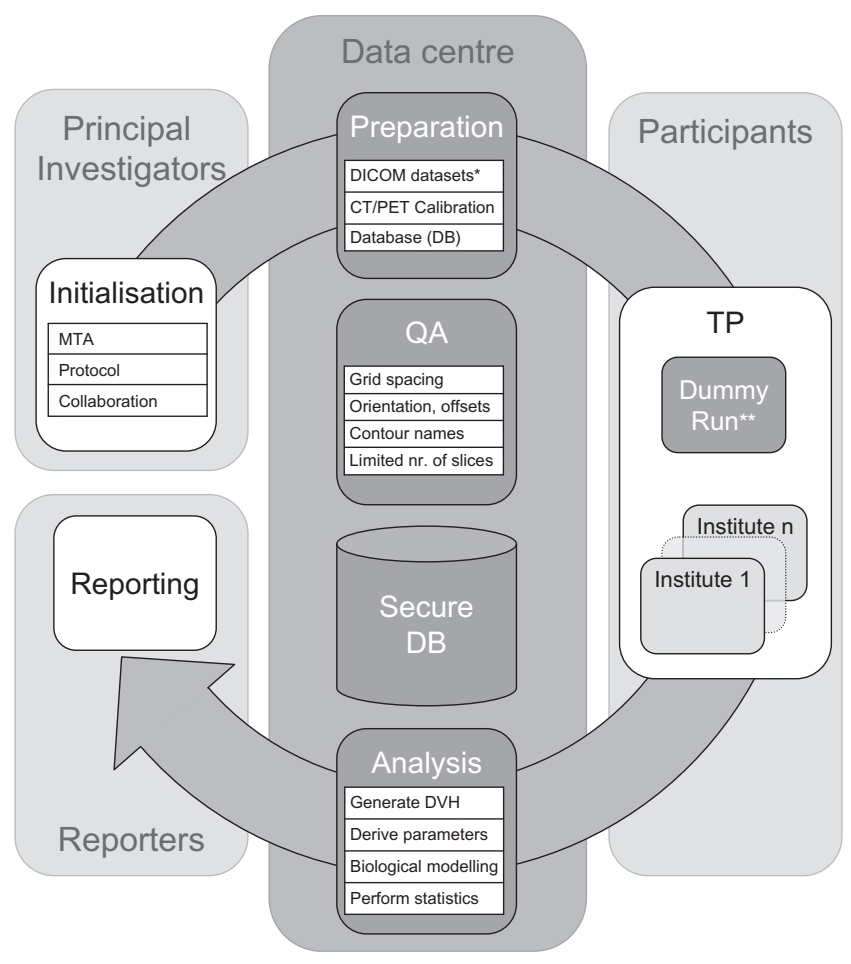

Fig. 1. A diagram illustrating the major actions of a project that is based on the currently presented in silico trial framework. After uploading data to the DB it is checked for integrity and validity by various QA procedures (some items shown). The blocks surrounded by the "Data centre" frame are performed centrally to avoid data corruption and minimise uncertainty due to the use of different algorithms. DICOM images can originate from multiple institutions. However, before allowing other participants to use them the DC performs the initial QA procedures. ${ }^{* *}$ The dummy run is a joint action by the DC and participants as part of the QA programme.
Medicine standards (DICOM) [13]. In the event of a participant being unable to comply, the RTOG (Radiation Therapy Oncology Group) format [14] was accepted.

The five action blocks of the framework, as described below, were: initialisation, preparation, treatment planning, analysis and reporting.

\section{Initialisation}

Following the template of a real clinical trial, a protocol was set up in which the trial hypothesis, the sample size and the methodology were described. The structure and management of the project were defined by project goals and milestones. With respect to the topic that was studied (the comparison of treatment techniques or modalities) the protocol described the study endpoints, differentiating primary and secondary endpoints and how differences were analysed. Furthermore, it described the available data and means to access it in a secure manner. A Material Transfer Agreement (MTA) was formulated in which the participants' roles, rights and liabilities were described. After signing the MTA, the participant was granted access to the central database. Templates of the protocol and MTA are available online.

\section{Preparation}

With the prepared protocol, eligible patients were accrued and their datasets were gathered. By consecutively including patients that satisfied the protocol, no selection bias was introduced. A set of CT images and delineations of targets and critical organs in the DICOM RT STRUCT format were de-identified and uploaded to the database. Furthermore, fluor-18-fluorodeoxyglucose (FDG) PET and MR images were added. For the available 4D CT/PET data, the 3D motion vector of the target was determined and included in the dataset [2]. Because the FDG-PET images were used to automatically delineate high-uptake regions with a method validated with pathology [15-17], the standardised uptake value (SUV) conversion curves of data-supplying institutes were calibrated [18]. This guaranteed that the auto-delineation algorithms used in the data-supplying institutes created equivalent contours.

\section{Treatment planning}

To perform TP, the centres downloaded the datasets from the database. It was mandatory for each centre to test if any shift occurred in the structure sets during data import. To validate the import, screen captures in JPG format of representative slices were uploaded for verification. The centre then proceeded with TP according to the strict criteria as described in the project protocol. The TP results were exported by the participants in DICOM RT format and uploaded to the DB.

\section{Analysis}

In order to analyse the results and to compare TP modalities, the DC used the CT, the delineations and the dose matrices stored in the DB. Visualisation of the TP results was done using MATLAB (The MathWorks, Natick, Massachusetts), CERR [19] or VODCA [20].

For the calculation of dose-volume histograms (DVHs), userdeveloped MATLAB code was used instead of requesting DVH parameters from the participants. The centrally performed calculations reduce any uncertainties that can arise due to differences in the algorithms of the various treatment planning systems (TPSs).

The DVHs were then used to derive relevant dose metrics of the different structures such as mean, maximum and minimum dose, conformity indices (CI), inhomogeneity coefficient (IC) and tumour 
control probability and normal tissue complication probability (TCP and NTCP, respectively) where models were available. The abovementioned metrics were calculated using the strict formulation described in the project protocol. The results were made available by entering them into the DB.

\section{Reporting}

Finally, the validated data in the DB were available for publication by the designated project members.

\section{Quality assurance}

A large collaborative project such as ROCOCO needs a well-designed data exchange set-up. Data supplied to all participants originate from multiple sources including CT, PET and MR scanners and from the TPS. TP will be based on the data available in the DB and participants will upload their data from their systems to the DB. Currently, TP has been performed using XiO/Focal (CMS Software, Elekta), Pinnacle (Philips), Virtuos/TRiP (in-house: DKFZ Heidelberg/GSI Darmstadt) and HIPLAN (in-house: NIRS). With such a variety of programmes involved and due to the fact that the DICOM standard allows vendors to incorporate proprietary information, interoperability problems easily arise with data import/export [21]. Therefore, it is essential to define a proper Quality Assurance (QA) programme.

At MAASTRO CLINIC, an in-house developed programme called DIGITrans is used in daily clinical routine that normalises all DICOM (RT) data to prevent interoperability issues and guarantees data consistency. This includes matching the patient demographics of exported data from the scanners, TPS or record-and-verifying system to the electronic health record. Furthermore, we "brand" the images by invisibly adding referencing DICOM tags to the image data.

During the set-up of the MISTIR framework many issues were addressed (Table 1) for which we reused part of the DIGITrans procedures or developed new ones. The MISTIR QA procedures now prevent and correct problems with:

- SUV (PET) calibration

- CT calibration (Hounsfield unit to electron density conversion)

- correct media assignment, if needed (e.g. in Monte Carlo dose calculations)

- DICOM (RT) data connectivity

- de-identification

- 4D data phase consistency

- orientation/transformation errors

- number of slices

- contour names

- contour interpolation

- multiple contours on a single slice

- invalid dose grid sizes

- other protocol violations.

To test the set-up of the protocol, DB and QA procedures, first a dummy run is performed with a representative sample of the dataset. The participants are asked to perform TP according to the protocol and send their results to the DB. Upon receiving the datasets, the QA procedures are applied to ensure consistency and validity of the data. In cases where the TP data do not conform to the protocol, the participant is asked to adapt its procedures and redo TP. Then the data are checked again for validity. After acceptance, the participant is asked to proceed with the entire dataset.

Table 1

A selection of problems, solutions and remarks on the implementation of the MISTIR QA procedures.

\begin{tabular}{|c|c|c|c|}
\hline Topic & $\begin{array}{l}\text { Problems occurred } \\
\text { during dummy run }\end{array}$ & Solution & Remarks \\
\hline De-identification & $\begin{array}{l}\text { The TPS, discards breathing phases in } 4 \mathrm{D} \\
\text { datasets, due to reduced DICOM references } \\
\text { in TPS export } \\
\text { The TPS does not handle PET or MR export }\end{array}$ & Write code to directly modify the needed tags & We use dcmodify from DCMTK ${ }^{\mathrm{b}}$ \\
\hline \multirow[t]{2}{*}{ Integrity } & $\begin{array}{l}\text { TPS changes coordinate systems during } \\
\text { DICOM import/export }\end{array}$ & $\begin{array}{l}\text { Check for transformations whenever data is entering } \\
\text { another system }\end{array}$ & $\begin{array}{l}\text { We use screenshots to visually } \\
\text { check for translations, rotations, } \\
\text { inversions etc. }\end{array}$ \\
\hline & $\begin{array}{l}\text { TPS drops the Frame of Reference UID during } \\
\text { DICOM import/export }\end{array}$ & Encode the Frame of Reference UID into the CT image data & $\begin{array}{l}\text { We use the offset vector to restore } \\
\text { transformed datasets }\end{array}$ \\
\hline \multirow[t]{2}{*}{ Slice thickness } & $\begin{array}{l}\text { TPS cannot handle CT images and contours } \\
\text { with varying slice thickness }\end{array}$ & $\begin{array}{l}\text { Resample the CT data, re-import into TPS and use the } \\
\text { interpolation function to generated contours on new slices. } \\
\text { Manually correct contours (e.g. in case of bifurcations) }\end{array}$ & \\
\hline & $\begin{array}{l}\text { TPS cannot handle difference in } \\
\text { reconstruction thickness and slice spacing }\end{array}$ & $\begin{array}{l}\text { Make the slice thickness equal to the difference between the } \\
\text { slice locations }\end{array}$ & $\begin{array}{l}\text { Radiologically this is not the same, } \\
\text { however, it can be ignored for } \\
\text { radiotherapy }\end{array}$ \\
\hline Nr. of slices & TPS could not handle $>99$ CT slices & $\begin{array}{l}\text { Make a subset of the data or resample if critical areas would } \\
\text { be cut off }\end{array}$ & $\begin{array}{l}\text { Add } \sim 5 \mathrm{~cm} \text { margin around beam } \\
\text { edges to account for patient } \\
\text { scatter }\end{array}$ \\
\hline Structure names & $\begin{array}{l}\text { TPS could not handle structure names } \\
\text { starting with a number }\end{array}$ & Change the structure name to begin with a letter & \\
\hline Internet protocols & $\begin{array}{l}\text { Secured network transfer between } \\
\text { institutes using FTPS not possible as the } \\
\text { protocol is often blocked by hospital } \\
\text { firewalls }\end{array}$ & Use an HTTPS as well as an FTPS server & $\begin{array}{l}\text { We use DRUPAL }{ }^{\mathrm{c}} \text { and FileZilla } \\
\text { Server }{ }^{\mathrm{d}} \text {, respectively. We use PKI } \\
\text { certificates to guarantee security }^{\text {. }}\end{array}$ \\
\hline File management & $\begin{array}{l}\text { An HTTPS server does not always allow } \\
\text { easy file manipulation }\end{array}$ & Add a module for file management & We use the WebFM module ${ }^{\mathrm{e}}$ \\
\hline Data corruption & $\begin{array}{l}\text { With many files in large datasets, upload is } \\
\text { prone to errors }\end{array}$ & Pack the datasets before upload & $\begin{array}{l}\text { We propose checksums to verify } \\
\text { data (e.g. MD5 or SHA1) }\end{array}$ \\
\hline
\end{tabular}

a Refer to MISTIR: http://www.mistir.info for more details.

b OFFIS Dicom Toolkit: http://dicom.offis.de/.

c DRUPAL: http://drupal.org.

d FileZilla: http://filezilla-project.org/.

e WebFM: http://drupal.org/project/webfm. 


\section{Results}

The presented MISTIR framework has been successfully used for a multicentric, in silico clinical trial that is currently being conducted by the ROCOCO consortium. Twelve institutes are participating and several more have expressed interest in the study.

To ensure data integrity, a series of QA tests were performed manually on any item (including that from the host institute) that is uploaded to the DB before releasing it to the project members. The QA procedures are designed to detect and correct issues regarding the readability of data, compatibility with DICOM (RT) standards and transformations in structure delineations and/or in image coordinates.

The design of the framework has successfully been tested for several different sectors of the trial. Implementation of the mentioned procedures has successfully led to TP results for prostate and lung cancer [22,23].

\section{Discussion}

We have demonstrated that building a functional data management and analysis framework for an international, multicentric in silico clinical trial are feasible. Its QA procedures are able to detect data inconsistencies and prevent incorrect data analysis.

In its current state, MISTIR is used for file-based data exchange and manual data analysis. To support large multicentric trials with improved data transfer and warehousing of the DICOM RT objects and data mining capabilities we are working on implementing a DICOM RT compliant DB (PACS). To ensure semantic and technical interoperability, recommendations from standardising initiatives for healthcare and clinical research such as caBIG [24], CDISC [25] and IHE [26] are taken into account.

One application that would strongly benefit from the availability of large validated, multicentric datasets is the modelling of radiotherapy outcome $[27,28]$. For satisfying significance of the predictive models a large number of datasets are necessary, while for robustness it is best to validate the models on foreign datasets. We believe that public sharing of these datasets would stimulate this research on a global scale, as it already has done in genomics research where public data repositories are common practice [29]. Whether a centralised set-up based on the current MISTIR platform is needed or that it should evolve into a de-centralised, grid-based solution such as the GridCAD and GridIMAGE initiatives for radiology $[30,31]$ remains to be determined. This is considered to be beyond the scope of this paper. A very recent series of papers of the QUANTEC consortium summarised the currently available dose/ volume/outcome data for normal tissues [32]. In a vision paper of the same series they concluded that storage of high quality datasets in repositories should become a common strategy [33]. We believe that the described technology will help to realise this goal.

\section{Conclusion}

We presented MISTIR: a complete and secure framework for in silico clinical trials using the output of treatment planning on prepared datasets. It is successfully being used in the in silico clinical treatment planning trial that the ROCOCO consortium currently is conducting. By defining strict planning protocols and using validated algorithms, the results of the in silico trials can be used as a starting point for validating and/or generating hypotheses, without harming any patient and at a reasonable cost. These hypotheses need further testing in prospective phase II/III trials.

The step-by-step description of the different building blocks and procedures that are used in MISTIR offer a useful guide for the set-up of future in silico trials and/or public repositories.

\section{Acknowledgments}

The ROCOCO members would like to specially thank Uwe Oelfke and Wolfgang Schlegel (Deutsche Krebsforschungszentrum, Germany), Marco Schwarz (Agenzia Provinciale per la Protonterapia, Italy) and Dietmar Georg (Medizinische Universität Wien, Austria) for their initial contribution to the project. Furthermore, dosimetrists who performed treatment planning are gratefully acknowledged.

\section{References}

[1] van Baardwijk A, Bosmans G, Bentzen SM, et al. Radiation dose prescription for non-small-cell lung cancer according to normal tissue dose constraints: an in silico clinical trial. Int J Radiat Oncol Biol Phys 2008;71:1103-10.

[2] Bosmans G, Buijsen J, Dekker A, et al. An "in silico" clinical trial comparing free breathing, slow and respiration correlated computed tomography in lung cancer patients. Radiother Oncol 2006;81:73-80.

[3] Jones B, Dale RG. Further radiobiologic modeling of palliative radiotherapy: use of virtual trials. Int J Radiat Oncol Biol Phys 2007;69:221-9.

[4] Brada M, Pijls-Johannesma M, De Ruysscher D. Current clinical evidence for proton therapy. Cancer J 2009;15:319-24.

[5] Goitein M, Lyman J, Maor M. Report of the working groups on the evaluation of treatment planning for particle beam radiotherapy. Bethesda, MD: Radiotherapy Development Branch, Research Program Division of Cancer Treatment, National Cancer Institute; 1987.

[6] Evaluation of high energy photon external beam treatment planning: project summary. Photon Treatment Planning Collaborative Working Group. Int J Radiat Oncol Biol Phys 1991;21:3-8.

[7] Qamhiyeh S, Pijls-Johannesma M, Verhaegen F, et al. ROCOCO: An International, Multicentric In Silico Clinical Trial in Lung, Prostate and Head \& Neck Cancer: Evaluation of Feasibility. Third International Conference on Translational Research and Pre-Clinical Strategies in Radiation Oncology 2009; Geneva, Switzerland.

[8] Securing FTP with TLS. The Internet Engineering Task Force (IETF), 2005. (Accessed January 21, 2010, at http://www.ietf.org/rfc/rfc4217.txt.).

[9] HTTP Over TLS. The Internet Engineering Task Force (IETF), 2000. (Accessed January 21, 2010, at http://www.ietf.org/rfc/rfc2818.txt.).

[10] Schutze B, Kammerer M, Klos G, Mildenberger P. The public-key-infrastructure of the radiological society of Germany. Eur J Radiol 2006;57:323-8.

[11] Pharow P, Blobel B. Public key infrastructures for health. Stud Health Technol Inform 2003;96:111-7.

[12] Internet X.509 Public Key Infrastructure Certificate and Certificate Revocation List (CRL) Profile. The Internet Engineering Task Force (IETF), 2008. (Accessed January 21, 2010, at http://www.ietf.org/rfc/rfc5280.txt.).

[13] American College of Radiology NEMA. ACR-NEMA digital imaging and communications standard: ACR-NEMA standards publication no. 300-1988. ACR-NEMA, 1988.

[14] Baxter BS, Hitchner Jr LE, GQM. AAPM Report No. 10: A Standard Format for Digital Image Exchange. American Association of Physicists in Medicine, 1982.

[15] Stroom J, Blaauwgeers H, van Baardwijk A, et al. Feasibility of pathologycorrelated lung imaging for accurate target definition of lung tumors. Int J Radiat Oncol Biol Phys 2007;69:267-75.

[16] van Baardwijk A, Bosmans G, Boersma L, et al. PET-CT-based auto-contouring in non-small-cell lung cancer correlates with pathology and reduces interobserver variability in the delineation of the primary tumor and involved nodal volumes. Int J Radiat Oncol Biol Phys 2007;68:771-8.

[17] van Baardwijk A, Bosmans G, van Suylen RJ, et al. Correlation of intra-tumour heterogeneity on 18F-FDG PET with pathologic features in non-small cell lung cancer: a feasibility study. Radiother Oncol 2008;87:55-8.

[18] Ollers M, Bosmans G, van Baardwijk A, et al. The integration of PET-CT scans from different hospitals into radiotherapy treatment planning. Radiother Oncol 2008;87:142-6.

[19] Deasy JO, Blanco AI, Clark VH. CERR: a computational environment for radiotherapy research. Med Phys 2003;30:979-85.

[20] VODCA: View-Oriented, Distributed, Cluster-based Approach. (Accessed February 24, 2010, at www.vodca.ch.).

[21] Henderson M, Behlen FM, Parisot C, Siegel EL, Channin DS. Integrating the healthcare enterprise: a primer. Part 4 . The role of existing standards in IHE. Radiographics 2001;21:1597-603.

[22] Roelofs E, Engelsman M, Rasch C, et al. Results of a multicenter in silico trial comparing photons and protons for radiotherapy of non-small cell lung cancer. Radiother Oncol 2009;92:S108.

[23] Meerleer GD, Roelofs E, Engelsman M, et al. To compare treatment planning results for primary radiotherapy of prostate cancer using proton, 3dimensional conformal and intensity modulated radiotherapy. 48th Meeting of the Particle Therapy Co-Operative Group 2009. doi:10.3205/09ptcog051.

[24] Fenstermacher D, Street C, McSherry T, Nayak V, Overby C, Feldman M. The cancer biomedical informatics grid ( $\left.\mathrm{caBIG}^{\mathrm{TM}}\right)$. Conf Proc IEEE Eng Med Biol Soc 2005;1:743-6.

[25] Souza T, Kush R, Evans JP. Global clinical data interchange standards are here! Drug Discov Today 2007;12:174-81. 
[26] Siegel EL, Channin DS. Integrating the healthcare enterprise: a primer. Part 1. Introduction. Radiographics 2001;21:1339-41.

[27] Dehing-Oberije C, Yu S, De Ruysscher D, et al. Development and external validation of prognostic model for 2-year survival of non-small-cell lung cancer patients treated with chemoradiotherapy. Int J Radiat Oncol Biol Phys 2009;74:355-62.

[28] El Naqa I, Bradley JD, Lindsay PE, Hope AJ, Deasy JO. Predicting radiotherapy outcomes using statistical learning techniques. Phys Med Biol 2009;54:S9-S30.

[29] Entrez Genome. (Accessed February 24, 2010, at http://www.ncbi.nlm.nih.gov/ sites/entrez?db=Genome.).
[30] Gurcan MN, Pan T, Sharma A, et al. GridIMAGE: a novel use of grid computing to support interactive human and computer-assisted detection decision support. J Digit Imaging 2007;20:160-71.

[31] Pan TC, Gurcan MN, Langella SA, et al. Informatics in radiology: GridCAD: gridbased computer-aided detection system. Radiographics 2007;27:889-97.

[32] Marks LB, Yorke ED, Jackson A, et al. Use of normal tissue complication probability models in the clinic. Int J Radiat Oncol Biol Phys 2010;76:S10-9.

[33] Deasy JO, Bentzen SM, Jackson A, et al. Improving normal tissue complication probability models: the need to adopt a "Data-Pooling" culture. Int J Radiat Oncol Biol Phys 2010;76:S151-4. 